\title{
Diet intervention and colon cancer recurrence: Nut consumption or Microbiota manipulation?
}

\author{
Daniel Herchenhorn* and Juliana Tarouquella \\ Grupo de Oncologia, D’Or Instituto D’ Or de Ensino e Pesquisa, Brazil
}

\begin{abstract}
The role of diet has been proved to be related to healthy habits and low risk of colon cancer. In contrast, some studies indicate that states of energy excess are associated with an increased risk of colon cancer recurrence and mortality. Therefore, the increase or reduction in the intake of certain foods that modify the hyperglycemic state should be related directly or secondary to the risk of colon cancer. As an example, seen in prospective studies, the increased nut intake has been associated with reduced risk of diabetes, metabolic syndrome and insulin resistance, and recently, was also associated in a prospective trial, to a reduced risk of colon cancer recurrence. Meanwhile, other studies have focused not only in the food components itself, but on microbiota characteristics to understand its importance for several chronic diseases, like inflammatory bowel disease, weight gain and including a higher chance of colon cancer. Recently, the so called fit-microbiota has been linked to improved response to immunotherapies in clinical as well as animal studies.
\end{abstract}

\section{Introduction}

Millions of bacteria contribute to the gut microbiota and this composition is specific for every individual [1]. Dietary patterns are associated with different combinations of bacteria in the intestine, with specific bacteria distribution, already linked with an increased or reduced risk of recurrence, mortality and chance of developing colon cancer $[1,2]$. Colon cancer is one of the most prevalent malignant tumors in the world and its primary prevention and reduction of recurrence is of great population interest.

Diets with a higher consumption of nuts seem to be related to a lower incidence of recurrence of colon cancer and it can be an indirect way of translating the manipulation of the intestinal microbiota naturally with a food intervention. This is a major issue for future opportunities on nutritional modulation of gut microbiome and food orientation to improve human health [1].

Innumerous interventional and observational studies evaluating diet components in several different cancer types have been published in the last years. Most of them, suffered from bias of inadequate sample, retrospective nature, non-controlled interventional therapies and different patient characteristics, making a consensus on specific diet supplementation, very difficult and creating a large amount of nonevidence-based recommendations.

\section{Focusing on diet supplements}

The role of specific diet patterns, like the amount of fiber use as well as a Mediterranean style, were long proved to be related to healthy habits and low risk of colon cancer [1]. In contrast, some studies indicate that states of energy excess (like type 2 diabetes, obesity, sedentary lifestyle, high intake of sugar, western-pattern diet) are associated with an increased risk of colon cancer recurrence and mortality, that may be, in part, by long term hyperinsulinemia [2-10]. Therefore, the increase or reduction in the intake of certain foods that modify the hyperglycemic state should be related directly or secondary to the risk of colon cancer.
As an example, seen in prospective studies, the increased nut intake has been associated with reduced risk of diabetes, metabolic syndrome and insulin resistance [11-18], and perhaps, with consequently reduced risk of colon cancer.

One of the major diet interventions to reduce colon cancer risk is the amount of fiber intake. Holscher HD et al. designed a controlled feeding randomized study with different servings/day of almonds, in amounts and processing form. They demonstrated that almond consumption induced changes in the microbiota and the degree of almond processing impacted the relative abundances of certains bacteria $[19,20]$. In this regard, looking specifically to tree nuts, including almonds and pistachio in particular, the effects of increased consumption were already corelated with gut microbiota composition in randomized cross-over human feeding studies [21]. The effect of pistachio consumption on gut microbiota was much stronger than the almond consumption but both appears to be an effective means of modifying this composition. Lamuel-Raventos RM et al. evaluated the prebiotics properties in humans of the non-bioaccessible material of nuts (polyphenols and polysaccharides), which provides substrates and bioactive metabolites for microbiota compounds, explaining in part the health benefits of nut consumption (Table 1) [22].

\section{Focusing on microbiota}

Other studies have recently focused not only in the food components itself, but on microbiota characteristics to understand its importance for several chronic diseases, like inflammatory bowel disease, weight gain and including a higher chance of colon cancer with certain microbioma sub-types [19,23].

${ }^{\star}$ Correspondence to: Daniel Herchenhorn, MD, PhD, Rua Sorocaba 464;408, Botaofogo, Rio de Janeiro RJ, Brazil, E-mail: herchenhorn@hotmail.com

Received: January 29, 2019; Accepted: February 21, 2019; Published: February 25,2019 
Table 1. Summary of trials focusing on diet intervention

\begin{tabular}{|l|l|l|}
\hline Author & Diet Intervention & Results \\
\hline Holscher HD et al. [20] & $\begin{array}{l}\text { Almond consumption in } \\
\text { different servings/day and } \\
\text { processing form }\end{array}$ & $\begin{array}{l}\text { Changes in the microbial } \\
\text { community composition of } \\
\text { the human gastrointestinal } \\
\text { microbiota. }\end{array}$ \\
\hline Maria Ukhanova et al. $[21]$ & $\begin{array}{l}\text { Almond and pistachio } \\
\text { consumption }\end{array}$ & $\begin{array}{l}\text { Increasing the consumption } \\
\text { of almonds or pistachios } \\
\text { appears to be an effective } \\
\text { means of modifying gut } \\
\text { microbiota composition. }\end{array}$ \\
\hline $\begin{array}{l}\text { Lamuel-Raventos RM } \text { et } \\
\text { al. } \text { [22] }\end{array}$ & Nut consumption & $\begin{array}{l}\text { Prebiotics properties of nuts } \\
\text { in humans. }\end{array}$ \\
\hline
\end{tabular}

As diets exhibits strong relation with the microbiota composition [1], and several studies now are looking for human colon cancer microbiome signatures, suggesting a fundamental rule of this components to the promotion of colon tumorigenesis, the importance of stablishing the specific influence of diet or microbiota is an important issue for patients and doctors, and play a critical role for surveillance measures in patients already diagnosed [19].

The gut microbiome diversity and high-fiber intake were also related to lower long-term weight gain in other trial [23]. Based on this study, gut microbiome composition seems to be related to weight change independently of calorie intake, physical activity and other potential confounders, because it could influence energy metabolism. The results suggest that the beneficial effect of fiber may be more pronounced in individuals with higher microbiome diversity and may reflect the fact that individuals with higher fiber intake have a greater microbiome diversity. The presence of Clostridiales and Ruminococcaceae family may simply reflect a correlation with microbiome diversity and the relative abundance of Bacteroides is correlated with lower microbiome diversity. This data highlights the complicated interaction between diet and intestinal bacteria composition to promote health benefits.

Since the gut microbiome is potentially modifiable, it can be seen not only as a predictive factor, but also as a future therapeutic target [23].

\section{Diet intervention and colon cancer recurrence}

Adding up to this complexity, the recently published CALGB 89803 trial raised the question of the importance of diet patterns and specifically, of nuts consumption, and its association with reduced incidence of cancer recurrence and death in stage III colon cancer, treated in a randomized controlled prospective trial [24].

This trial was a unique effort in combining an intense and detailed dietary assessment in this prospective chemotherapy trial. The impact of nut intake was examined and controlled for other confounders, and its relative benefit appeared to be unchanged, showing a great benefit independent of diet patterns, disease characteristics as well as type of chemotherapy that was offered. The median follow-up time was 6,5 years, and 199 of the 826 patients progressed with recurrence or developed new primary tumors. Of the total of 826 patients, 177 died, and 39 patients died without evidence of documented cancer recurrence. The impact of nut consumption was associated with statistical and clinically significant reduction in recurrence and mortality for colon cancer after adjusting for other predictors of risk. Those who consumed diets with two or more serving nuts per week demonstrated adjusted hazard ratio for disease-free survival of 0,58 . Higher nuts intake also demonstrated significant improvement in overall survival with a hazard ratio of 0,43 , when compared with patients who abstained about this intake. These results appeared superior to several toxic and expensive measures already tried in adjuvant setting, reinforcing the role of lifestyle, including controlled diet, as critical components of cancer prevention as well as treatment [24].

Unfortunately, a point of interest, that was not assessed, due to the nature of this randomized prospective trial, was information on gut microbiota composition as an independent prognostic factor.

There appears to be a direct relationship between the microbiota composition and factors such as immunogenicity, increased or reduced risk of cancer incidence, and response to certain new treatments, in particular immunotherapy. Thus, the information of patient's microbiota composition with a nut enriched diet is extremely important and valid for the understanding and determination of the real cause and effect relationship between the consumption of these foods and possible changes in the microbiota as a consequence of this intake and, finally, justifying the reduction in the incidence of colon cancer recurrence as presented in the study.

Is it the direct benefit of the consumption of nuts or the secondary alteration of the composition of the intestinal microbiota caused by the consumption of nuts and a healthier diet?

If the fit composition of the microbiota is the responsible for the benefit in reducing the risk of recurrence of colon cancer, other ways of manipulating the microbiota may be seen as forms of prevention and could be used as adjuvant strategies for disease recurrence and maybe treatment response.

Although nut consumption could be an easy way of providing the benefits of a healthy and fit microbiome for colon cancer patients, the real question mentioned in the article is: what are the "other possible mechanisms through which nut intake may influence survival in patients with colon cancer" (Table 2).

\section{Microbiota and immunotherapy}

Looking for the importance of microbiota to tumor carcinogenesis, immunogenicity and how it can be manipulated based on diet components, in special regarding nut consumption, it seems possible that the real effect of nuts on cancer relapse and survival, maybe, at least in part, mediated not by its antioxidants or anti-inflammatory properties, but by an increase in certain "good" bacteria compositions.

The attention to the importance of gut microbiota was again evaluated in a recent study looking for different microbiota compositions and it's relation to response to immunotherapy (check-point inhibitors). In this study, fecal components of what was called as "fit microbiota" (high diversity and abundance of Ruminococcaceae/Faecalibacterium) were associated to higher immunotherapy responses in patients. In the same article and was also replicated when evaluated in mouse models, with implanted melanoma and exposition to different fecal components (from responders and no responders). The results indicate that the gut microbiome may modulate responses to immunotherapy, serving as a potential biomarker for therapy response but also as a potential therapy sensitizer. Probably, patients with a favorable gut microbiome have enhanced systemic and anti-tumor immune responses mediated by increased antigen presentation and improved effector $\mathrm{T}$ cell function in the periphery and the tumor microenvironment. This is further proof of the importance of microbiota components as a way of improving host immune response $[25,26]$.

Others similar studies evaluated microbiota composition as a contributing factor for the response to immunotherapy [27-29]. Despite a small sample size, in the first study, patients with different compositions of the intestinal microbiota presented differences in the 
Table 2. Summary of trials focusing on microbiota and colon cancer recurrence

\begin{tabular}{|l|l|l|}
\hline Author & Intervention & Results \\
\hline C. Menni et al. [24] & $\begin{array}{l}\text { Gut microbiome in fecal samples, weight gain and fiber } \\
\text { intake }\end{array}$ & $\begin{array}{l}\text { High gut microbiome diversity, high fiber intake and operational taxonomic units are } \\
\text { correlated with lower term weight gain in humans independently of calorie intake. }\end{array}$ \\
\hline Temidayo Fadelu et al. $[31]$ & Dietary intake in patients with stage III colon cancer & $\begin{array}{l}\text { Diets with a higher consumption of nuts may be associated with a reduced incidence of } \\
\text { cancer recurrence and death in patients with stage III colon cancer. }\end{array}$ \\
\hline
\end{tabular}

Table 3. Summary of trials that evaluated microbita and immunotherapy

\begin{tabular}{|l|l|l|}
\hline Author & Diet Intervention & Results \\
\hline V. Gopalakrishnan et al. [23] & $\begin{array}{l}\text { Diversity microbiota in human fecal samples analysis and } \\
\text { fecal microbiome transplantation in mices. }\end{array}$ & $\begin{array}{l}\text { Gut microbiome may modulate responses to anti-PD-1 immunotherapy in melanoma } \\
\text { patients. }\end{array}$ \\
\hline Brandilyn Peters et al. [25] & $\begin{array}{l}\text { Microbiome bacterial community analysis, diversity, and } \\
\text { taxon abundance, in relation to time to disease progression } \\
\text { in stage 3-4 melanoma patients in immunotherapy. }\end{array}$ & $\begin{array}{l}\text { Higher community diversity of microbiome was associated with lower risk of } \\
\text { progression. Gut microbiome is associated with response to immunotherapy, suggestive } \\
\text { that microbiome manipulation may improve immunotherapy outcomes. }\end{array}$ \\
\hline Lisa Derosa et al. [26] & $\begin{array}{l}\text { Human fecal sample analysis, fecal microbiota } \\
\text { transplantation and resistance to anti-PD-1. }\end{array}$ & $\begin{array}{l}\text { Composition of gut microbiome may predict resistance to anti-PD-1 in renal cancer cell } \\
\text { patients. Interventions to modulate gut microbiome may represent strategies to improve } \\
\text { clinical outcomes. }\end{array}$ \\
\hline
\end{tabular}

risk of progression, once again, the presence of Faecalibacterium was associated with a significant risk reduction. Ruminococcus presence was related to an increase in the risk of progression. Thus, it suggests that manipulation of the microbiome may improve the clinical results of immunotherapy [27].

A second trial evaluated the impact of microbiome in renal cell carcinoma patients. In that study, renal cell carcinoma patients treated with nivolumab in the NIVOREN study had fecal samples collected and classified as primary resistance or non-primary resistance, following RECIST classification. Next, mice with primary resistance received fecal microbiota transplantation from primary non-resistance patients, and were able to demonstrate restoration of treatment responsiveness, suggesting a cause-effect relationship between dysbiosis and resistance. Thus, authors concluded that the composition of the intestinal microbiome may predict resistance to anti-PD-1 in patients with renal cell carcinoma and interventions that modulate the intestinal microbiome may represent strategies to improve clinical outcomes with immunotherapy [28].

Another important issue to be mentioned is the recent evidence that the use of antibiotics may alter the composition of the microbiota and compromise the response to immunotherapy [28-31]. This has been observed in different solid tumors, such as melanoma, renal and lung cancer $[28,30,31]$. In lung cancer patients, the use of antibiotics in patients with immunotherapy is frequent. In a retrospective analysis, a reduction in overall survival was observed in the group of patients treated with nivolumab who underwent antibiotic therapy, which could be attributed to the primary resistance to immunotherapy due to the use of antibiotics and perhaps consequent alteration of the intestinal microbiota (Table 3) [30].

\section{Conclusion}

In this scenario, future prospective randomized trials focusing not only on diet interventions, but also looking for microbiota components, should be attempted.

In the era of personalized as well as immunotherapy therapies, with a major deficit when looking for predictive biomarkers, gut microbiome raises as a cheaper, healthier and a better way to understand how patient's characteristics could impact on its response to therapy as well as to provide better understanding of ways to prevent disease development and relapse.

Nuts may be an easy way to improve our own flora condition, but just markers of what we really need to feed and balance to be able to fight against the disease.

\section{References}

1. Graf D, Di Cagno R, Fåk F, Flint HJ, Nyman M, et al. (2015) Contribution of diet to the composition of the human gut microbiota. Microb Ecol Health Dis 26: 26164. [Crossref]

2. Meyerhardt JA, Sato K, Niedzwiecki D, Ye C, Saltz LB, et al. (2012) Dietary glycemic load and cancer recurrence and survival in patients with stage III colon cancer: Findings from CALGB 89803. J Natl Cancer Inst 104: 1702-1711. [Crossref]

3. Meyerhardt JA, Heseltine D, Niedzwiecki D, Hollis D, Saltz LB, et al. (2006) Impact of physical activity on cancer recurrence and survival in patients with stage III colon cancer: Findings from CALGB 89803. J Clin Oncol 24: 3535-3541. [Crossref]

4. Meyerhardt JA, Niedzwiecki D, Hollis D, Saltz LB, Hu FB, et al. (2007) Association of dietary patterns with cancer recurrence and survival in patients with stage III colon cancer. JAMA 298: 754-764. [Crossref]

5. Meyerhardt JA, Niedzwiecki D, Hollis D, Saltz LB, Mayer RJ, et al. (2008) Impact of body mass index and weight change after treatment on cancer recurrence and survival in patients with stage III colon cancer: Findings from Cancer and Leukemia Group B 89803. J Clin Oncol 26: 4109 4115. [Crossref]

6. Meyerhardt JA, Giovannucci EL, Holmes MD, Chan AT, Chan JA, et al. (2006) Physical activity and survival after colorectal cancer diagnosis. J Clin Oncol 24: 35273534. [Crossref]

7. Dignam JJ, Polite BN, Yothers G, Raich P, Colangelo L, et al. (2006) Body mass index and outcomes in patients who receive adjuvant chemotherapy for colon cancer. $J$ Natl Cancer Inst 98: 1647-1654. [Crossref]

8. Meyerhardt JA, Catalano PJ, Haller DG, Mayer RJ, Macdonald JS, et al. (2003) Impact of diabetes mellitus on outcomes in patients with colon cancer. J Clin Oncol 21: 433440. [Crossref]

9. Fuchs MA, Sato K, Niedzwiecki D, Ye X, Saltz LB, et al. (2014) Sugar-sweetened beverage intake and cancer recurrence and survival in CALGB 89803 (Alliance). PLoS One 9: e99816. [Crossref]

10. Wolpin BM, Meyerhardt JA, Chan AT, Ng K, Chan JA, et al. (2009) Insulin, the insulin-like growth factor axis, and mortality in patients with nonmetastatic colorectal cancer. J Clin Oncol 27: 176-185. [Crossref]

11. Casas-Agustench P, López-Uriarte P, Bulló M, Ros E, Cabré-Vila JJ, et al. (2011) Effects of one serving of mixed nuts on serum lipids, insulin resistance and inflammatory markers in patients with the metabolic syndrome. Nutr Metab Cardiovasc Dis 21: 126135. [Crossref]

12. Holligan SD, West SG, Gebauer SK, Kay CD, Kris-Etherton PM (2014) A moderatefat diet containing pistachios improves emerging markers of cardiometabolic syndrome in healthy adults with elevated LDL levels. Br J Nutr 112: 744-752. [Crossref]

13. O’Neil CE, Fulgoni VL III, Nicklas TA (2015) Tree nut consumption is associated with better adiposity measures and cardiovascular and metabolic syndrome health risk factors in U.S. adults: NHANES 2005-2010. Nutr J 14: 64. [Crossref]

14. Ros E (2010) Health benefits of nut consumption. Nutrients 2: 652-682. [Crossref]

15. Hernández-Alonso P, Salas-Salvadó J, Baldrich-Mora M, Juanola-Falgarona M, Bulló M (2014) Beneficial effect of pistachio consumption on glucose metabolism, insulin resistance, inflammation, and related metabolic risk markers: A randomized clinical trial. Diabetes Care 37: 3098-3105. [Crossref] 
16. Jenkins DJ, Kendall CW, Josse AR, Salvatore S, Brighenti F, et al. (2006) Almonds decrease postprandial glycemia, insulinemia, and oxidative damage in healthy individuals. J Nutr 136: 2987-2992. [Crossref]

17. Jiang R, Jacobs DR Jr, Mayer-Davis E, Szklo M, Herrington D, et al. (2006) Nut and seed consumption and inflammatory markers in the multi-ethnic study of atherosclerosis. Am J Epidemiol 163: 222-231. [Crossref]

18. Sweazea KL, Johnston CS, Ricklefs KD, Petersen KN (2014) Almond supplementation in the absence of dietary advice significantly reduces C-reactive protein in subjects with type 2 diabetes. J Funct Foods 10: 252-259.

19. Tilg H, Adolph TE, Gerner RR, Moschen AR (2018) The intestinal microbiota in colorectal cancer. Cancer Cell 33: 954-964. [Crossref]

20. Holscher HD, Taylor AM, Swanson KS, Novotny JA, Baer DJ (2018) Almond consumption and processing affects the composition of the gastrointestinal microbiota of healthy adult men and women: A randomized controlled trial. Nutrients 10. [Crossref]

21. Ukhanova M, Wang X, Baer DJ, Novotny JA, Fredborg M, et al. (2014) Effects of almond and pistachio consumption on gut microbiota composition in a randomised cross-over human feeding study. Br J Nutr 111: 2146-2152. [Crossref]

22. Lamuel-Raventos RM, Onge MS (2017) Prebiotic nut compounds and human microbiota. Crit Rev Food Sci Nutr 57: 3154-3163. [Crossref]

23. Menni C, Jackson MA, Pallister T, Steves CJ, Spector TD, et al. (2017) Gut microbiome diversity and high-fibre intake are related to lower long-term weight gain. Int J Obes (Lond) 41: 1099-1105. [Crossref]
24. Fadelu T, Zhang S, Niedzwiecki D, Ye X, Saltz LB, et al. (2018) Nut consumption and survival in patients with stage III colon cancer: Results from CALGB 89803 (Alliance). $J$ Clin Oncol 36: 1112-1120. [Crossref]

25. Gopalakrishnan V, Spencer CN, Nezi L, Reuben A, Andrews MC, et al. (2018) Gut microbiome modulates response to anti-PD-1 immunotherapy in melanoma patients. Science 359: 97-103. [Crossref]

26. Gopalakrishnan V, Helmink BA, Spencer CN, Reuben A, Wargo JA (2018) The influence of the gut microbiome on cancer, immunity, and cancer immunotherapy. Cancer Cell 33: 570-580. [Crossref]

27. Peters B, Wilson M, Moran U, Pavlick AC, Izsak A et al. (2018) Gut microbiome and immunotherapy response in melanoma patients. J Clin Oncol.

28. Derosa L, Iebba V, Albiges L, Fidelle M, Bonvalet M, et al. (2018) Gut microbiome composition to predict resistance in renal cell carcinoma (RCC) patients on nivolumab. J Clin Oncol 36.

29. Routy B, Le Chatelier E, Derosa L, Duong CPM, Alou MT, et al. (2018) Gut microbiome influences efficacy of PD-1-based immunotherapy against epithelial tumors. Science 359: 91-97. [Crossref]

30. Do TP, Hegde AM, Cherry CR, Stroud CRG, Sharma N, et al. (2018) Antibiotic use and overall survival in lung cancer patients receiving nivolumab. J Clin Oncol 36.

31. Thompson J, Szabo A, Arce-Lara C, Menon S (2017) Microbiome \& immunotherapy: Antibiotic use is associated with inferior survival for lung cancer patients receiving PD-1 Inhibitors. $J$ Thorac Oncol.

Copyright: (C)2019 Herchenhorn D. This is an open-access article distributed under the terms of the Creative Commons Attribution License, which permits unrestricted use, distribution, and reproduction in any medium, provided the original author and source are credited. 